\title{
The Evolution of Logo Design Styles Forms
}

\author{
Xiaowei Zhang \\ Yantai Nanshan University \\ Longkou, Shandong, China
}

\begin{abstract}
Modern mass communication symbol logo design is a special kind of text or image composition, its basic function is to convey graphical information, the performance of its intrinsic quality, features, and as a means of communication with the media; it is human civilization high capacity carrier, is the epitome of human culture. Throughout history, from primitive society to mark the totem from the Shang and Zhou Qin and Han pictograph to seal, from the Tang and Song to the Ming and Qing guise of westernized flags that these changes are all embodied the history and culture of society as a whole situation. We can borrow during the modern logo design symbolic of the original symbol reflects some charm, emotion and thought; or to carry out certain elements of the original symbol of change, restructuring and new, it has a traditional shape and charm, but also modern design means; or to penetrate the traditional methods of modern graphic logo design among thereby reflecting a region, a nation's temperament, spirit and philosophy. Summary Modern logo design style and form characteristics, to further explore the characteristics and style of the logo design process to analyze the evolution of the form, to predict its development trend, pointing out future logo design will be diverse design, design technology, the promotion of human design freedom and liberation.
\end{abstract}

Keywords-logo design; style; evolution; developing trend

\section{INTRODUCTION}

Logo design future direction, in fact, every designer will have their own views. I'm here is I after a long period of observation and accumulated some experience and lessons. Logo design to the development of modern times has been quite mature, mainly in its artistic standards, applied. Widely used three-dimensional modeling: the more three-dimensional mark, by an unprecedented three-dimensional modeling to convey visual information more visual appreciation dimensional modeling, signs can be divided into threedimensional shape on several levels in more detailed area. Material and gloss applications: sign out of the past solid fill constraints, have more abundant blending materials and luster, this design style also affected neighboring areas of design styles. More complex vividly: Object Logo design is no longer just a simple shape rigid, more artistic and expressive image after another. Sources greatly enriched the creative design, and even to some extent draws illustration design style. With the increasingly frequent international exchanges, logo visual image, without language barriers and other features extremely conducive to the exchange and application of international, the international symbol of the rapid promotion and development, has become one of the most effective means of conveying visual. It has become a common human visual contact tool.
New trends in logo design, green design concept is introduced, natural rhyme of the pursuit of beauty, multidimensional space image of the logo design, fashion design and pleasant language, logo design and combination of traditional culture and so on. Followed by analysis describes our colorful traditional graphics resource, and pointed out the blending of traditional graphics and logo design office. In the fourth chapter, focuses on the characteristics of the modern logo design traditional pattern, traditional graphic logo design new trends in the application of value meaning (including the needs of the people of modern consumer culture, product logo design needs of traditional culture in the logo design the use of traditional graphics to better highlight the national identity and logo design application in the traditional pattern is a heritage of traditional culture), and analyzed the substance of traditional graphic logo design trends in new applications: shape borrow, extend and meaning God's inheritance, the last of the traditional graphics and logo design combination of new trends were discussed, mainly in three aspects: the traditional pattern of the original abstract, original traditional pattern reconstruction and extension of traditional graphic imagery in logo design . In the last part of this paper, the research work of this paper to do a section, and the prospect of further research work done.

\section{LOGO DESIGN STYLE AND ForM OF THE EVOLUTION OF THE TIMES}

\section{A. Logo Design Before the Industrial Revolution}

In the logo design activities before the industrial revolution of the eighteenth century, basically handicraft centered activities. Logo designers and creators often from the same people hand, and logo design service objects are just the upper class elite, elite and aristocracy. Therefore, in the logo design style naturally appeared pretense, affectation of "fashion" style. During this period, the main purpose of logo design is to design for the royal and aristocratic emblems and leave a special mark on the arts and crafts.

\section{B. Logo Design Arts and Crafts Movement}

In 1851, the Crystal Palace in London World's Fair began, "Arts and Crafts" movement, that "under the tutelage of nature" and the Gothic Revival style, focusing on rationality and perfect unity Deco design. Logo design in this movement also showed a clear style characteristics of the times. Widespread use of animal and plant patterns in logo design, simple and generous. Victoria pretense, luxury fashion, using simple medieval style, drawing on natural decorative textures, 
creating a very different historical retro style new design style. [1] However, the logo design Arts and Crafts Movement was the industrial revolution countries escape fantasy. Social development, the logo design style of this period is negative, therefore, Arts and Crafts Movement logo design does not become a leader in the trend of the mainstream style, but because of the exquisite sound design principles for the future in the wake of the designer logo designed to provide a new design style reference.

\section{Logo Design Art Nouveau and Art Deco Period}

Art Nouveau cause initiated by the nineteenth-century Europe filled with tedious mannered Victorian decor aroused strong dissatisfaction. Logo design style of this period is based on oriental art reference, artificial style of negation. Instead focus emphasizes expressive decorative treatment and emphasize lines. Delicate style, decorative particularly strong feature of this period is a common representation of the design. Art Deco period of logo design style, one is looking for inspiration from ancient Egypt luxurious decorative elements, the simple geometric shapes, architectural design, the use of metal color and black and white series series reached a high decorative effect, give the designer great inspiration; on the other hand, the impact of primitive art, particularly in Africa and South America tribes of. So simple geometric shapes characteristic of the times became the designers are keen study, the focus performance. Art Deco period style logo design is the interface between Arts and Crafts Movement design style and modernist style between. Flag Art Deco period of design starting from decorative forms, take the principle of eclecticism, crafts and exploring the integration of industrialization and development of a new logo design. It is decorated in the style of 1980s modernism became the logo design research.

\section{Modern Era Logo Design}

Now ism logo design emphasizes harmony and unity, like to use simple geometry rational composition, shape, decoration against the doctrine, that "decoration that is evil," "Beauty in proportion" and so on. This period almost all of logo design with a compass and straightedge plotted geometry. Such as the famous symbol of Japan's Mitsubishi Heavy Industries, is composed of three simple heart made of diamond are arranged to form a stable pyramid shape. Although modernism logo design stresses functionality, object-oriented nature of the service, the pursuit of simple, clear visual effect, but likely to cause design works apathy, severe rational appearance, style monotonous, impersonal. Induction Modern Era logo design style: decorative opposition, emphasizing the rational, less is more.

\section{E. Post-modernist Era Flag Design Style and Its Development Trend}

The socio-economic development stimulated the reform of art logo design, logo design perfect not just function, including decoration design aesthetic content, hoping to use the details of decoration and relaxed stretch to reach the visual, the pursuit of humane, decorative and change the traditional form of individuality. At this time, post-modernist design style emerged. After ism logo design style should now be regarded as a new standard for logo design exploration, modernist style logo design improvements, additions and development. Is the development challenges of extreme monopoly modernist style logo design launched, Innovation and change is the impact of the new generation of designers Monotonous logo design style. Postmodernism is not a simple logo design style intact natural history of recovery, and refining methods to be taken, mixing, stitching, logo design modernist style, eclectic aesthetic basis for treatment standards.

Visible, logo design evolved from the pursuit of the surface to decorate for the purpose of conveying information to establish a process of evolution. Most traditional signs evolved from simple to complicated, as evolved from having to abstract, from the identification of the evolution of decorative aptitude. Flag has been many years in the pursuit of planarization, Simplification, monochromatic, abstract design, its performance is primarily designed to follow the rules of formal beauty to the point, line, surface composition generalize, the use of two-dimensional visual effects, this was largely due to the underdevelopment of Engraving and printing, the production process and the cost of the means of communication and other restrictions.

\section{NEW TREND OF CONTEMPORARY LOGO DESIGN}

\section{A. Diversified Development Trend}

With the progress of the information age and the development of science and technology dissemination media diversity, reflected in a sign of the future at the same connotation, will cover a variety of forms, means and forms, the pursuit of individuality performance, focusing on visual effects will gradually diversified into a species new design trends. While retaining the traditional form of the plane at the same time, many signs have adopted a gradual, realistic, threedimensional, and even pictures and other forms, making the previous single sign forms become rich "multi-dimensional" look, in order to attract attention, these changes will undoubtedly to establish a brand image to liven up.

\section{B. Humanized Development Trend}

Future logo design should be people-oriented, the pursuit of modern humane, decorative changes, there are manifestations of personality, not just request flag improve the function, but also meet the needs of aesthetic.

\section{Entertainment Development Trend}

Entertainment is the future development trend of a logo design, modern urban intense pace of life makes people more willing to accept from a visual, psychological feel relaxed and comfortable visual information, in order to meet new cultural needs of the future logo design might having a little banter, ridicule colors. For example, a humorous style logo design, less serious rational expression, a more relaxed. In addition, the sentimental hand-painted sign is now also increasingly more up, its simple and natural style with unparalleled charm and humanity the arts and humanities color. 


\section{Science and Technology Development Trend}

Further development of technology and the level of printing technology, logo design on the technique of expression has been an unprecedented strengthening rich, no longer confined to the two-dimensional plane, many wonderful ideas can be realized. Image Communication logo, visual impact, embodies the personality and so has a greater performance tension. Logo design appeared in pictures, paintings, and other forms of three-dimensional space, and some use of Chinese calligraphy, carving, ink and other performance practices, and even the use of a transparent layer, high light, shadow, and other realistic performance metallic effect.

\section{CONCLUSION}

Logo design is a kind of modern mass communication symbol symbolic special text or image composition, it must be refined to convey the image information, the performance of its intrinsic quality, features, and with it as a communication medium. Flag, as a special form of human visual contact, not only in social activities and production activities everywhere, and for the fundamental interests of the state, social groups and individuals, more unique exhibits an extremely important function. Chinese logo design from scratch, from the initial prototype to the original lute and seal system to today's corporate image is accompanied by the occurrence of human civilization, the development, along with the occurrence and development of commodity production and exchange arising and Forming. It has been a long history.

Early signs for the West, we can reasonably believe that the social status symbol and a variety of certificates of origin need to work together with the desire results. Similarly, we can assume that stigma, ear tags and farm safety is due to the need signs almost born. In modern times, with the development of graphic design, logo design thinking has gone through several evolution. Our simple analysis of each design in modern mainstream design, logo design and the impact on produce. In fact, our current design all kinds of popular styles logo, are derived from a variety of modern and contemporary logo design. Modern logo design as the main form of visual communication, has gone from industrial society to the information age, the design concepts of many changes.

Logo design in function, form, language and performance, much of Eastern and Western cultural trends and the art style of, pay attention to the concept of intervention in the human way of life, guiding thinking, emotional expression and graphics creation. We found that in the past the use of flags in the habit of breaking the law is inherent symbolic phenomenon is deconstructed, people find a unifying factor inherent natural vision from a fixed sign, which is the progress of graphics research, but also signs of liberation, human across the centuries to find a rationalization of mileage visual space, forming a large diversified development trend of modern logo design. We analyzed the flag of each period of the evolution of style, to find out the causes of these changes is to better understand the past and seize the future. Then enumerated some of the recent trend of Chinese and foreign flag design. Of course, it is very one-sided, but we can not predict that overall, we are trying to find out some small change flag design - can be said to call or dynamic. Logo design into the culture and design skills too much, designers can fully play to their imagination to create more high-impact logo works. Powerful software ILLUSTRATOR of all our imagination into reality. The development of technology has changed the traditional logo design pattern can be predicted that the future will no longer be just a sign of weak image that it will be a more diversified, humane form to show in front of people.

In summary, this trend extends the meaning and significance of logo, logo design is the inevitable choice of development with the times and development. Any design must keep up with the times, logo design is no exception, because of a design style social and historical background, human needs and market-oriented changes being replaced by another design style, which is the inevitable trend of development.

\section{REFERENCES}

[1] Qianfenggen. Introduction to modern Western design [M]. Chongqing : Southwest China Normal University Press, 2001: 155

[2] Wangshouzhi. World History of Modern Graphic Design [M]. Beijing: China Youth Press, 2002: 96.

[3] John chacara. Modernist design of future [M]. Beijing: Renmin University of China Press,2000: 78.

[4] zhangxue. Postmodern logo design [M] guangzhou: Lingnan Fine Arts Press, 2003: 119. 